\title{
ANÁLISE LINGUÍSTICA MEDIADA POR JOGOS
}

\section{LINGUISTIC ANALYSIS MEDIATED BY GAMES}

\author{
Kiahra Antonella Coelho Pereira* \\ Wagner Rodrigues Silva** \\ Jose Robson Mariano Alves ${ }^{* * *}$
}

\begin{abstract}
Resumo: Este artigo apresenta uma experiência pedagógica sobre uma prática escolar de análise linguística mediada por jogos analógicos e digitais, produzidos para aulas de Português como língua materna, por uma professora de um curso de formação de técnicos de informática. A experiência foi desenvolvida para minimizar alguns problemas linguísticos identificados na escrita discente e para desenvolver o conhecimento gramatical explícito dos alunos. A estratégia pedagógica diferenciada despertou o interesse dos alunos para o estudo da língua materna e, conforme entendimento da professora, o conhecimento explícito de aspectos sintáticos e semânticos da língua materna pode contribuir para o desenvolvimento do raciocínio abstrato discente, o que é demandado em outros componentes curriculares, quando os alunos estudam algumas linguagens de programação de sistemas para computadores.
\end{abstract}

Palavras-chave: gramática; texto; material pedagógico.

Abstract: This article presents a pedagogical experience about a school practice of linguistic analysis mediated by analogue and digital games, produced for classes in Portuguese as a mother tongue, by a teacher in a computer technicians training course. The experience was developed to minimize some linguistic problems identified in student writing and to develop students' explicit grammatical knowledge. The differentiated pedagogical strategy aroused the students' interest for the study of the mother tongue and, according to the teacher's understanding, the explicit knowledge of syntactic and semantic aspects of Portuguese can contribute to the development of their abstract thinking, which is required in other subjects, when students study some computer system programming languages.

Keywords: grammar; text; teaching material.

\section{Introdução}

Ao ministrar aulas para jovens em um curso técnico noturno, em que muitos deles exercem atividades laborais ou escolares no período diurno, o ensino orientado por abordagens transmissivas pode se tornar pouco produtivo, deixando os alunos ainda mais exaustos ${ }^{1}$. Nessas condições, restam duas opções ao professor: ignorar os sinais negativos dados pelos alunos, permanecendo adepto à reprodução do conteúdo disciplinar selecionado, ou enfrentar o desafio por considerar a realidade social em que estão inseridos os alunos, alterando as bases metodológicas em função de um processo de aprendizagem mais ativo e dinâmico.

Alguns estudantes chegam à modalidade técnica de ensino descrentes nos próprios conhecimentos, incluindo aí saberes linguísticos garantidores do uso do português como língua materna. Como as habilidades linguísticas são indispensáveis

\footnotetext{
*Doutoranda em Letras: Ensino de Língua e Literatura, na Universidade Federal do Tocantins (UFT). Professora EBTT no Instituto Federal do Tocantins (IFTO). E-mail: kiahra.antonella@ ifto.edu.br

** Doutor em Linguística Aplicada, Docente na Universidade Federal do Tocantins (UFT), Bolsista de Produtividade em Pesquisa do CNPq. E-mail: wagnersilva@uft.edu.br.

${ }^{* * *}$ Mestre em Modelagem Computacional do Conhecimento. Professor EBTT no Instituto Federal do Tocantins (IFTO). E-mail: jose.alves@ifto.edu.br

${ }^{1}$ No Câmpus Avançado de Lagoa da Confusão, do Instituto Federal do Tocantins (IFTO), local da experiência de ensino focalizada neste artigo, os cursos técnicos funcionam na modalidade concomitante e subsequente. No primeiro caso, os alunos cursam simultaneamente o Ensino Médio em escolas públicas ou particulares, ao passo que, no segundo caso, os alunos já concluíram o Ensino Médio.
} 
para o trânsito discente na educação formal, visto que os saberes técnicos ou especializados a serem apreendidos perpassam por práticas de leitura e de escrita, faz-se necessário um trabalho de conscientização linguística. Em outras palavras, demanda-se do professor o esforço para levar os alunos a compreenderem o funcionamento dos sistemas internos à gramática do português, assim como operarem concretamente sobre o funcionamento da língua, tal qual as diferentes linguagens de programação a que precisam se apropriar no curso Técnico em Informática.

Além disso, a maioria dos estudantes está inserida em uma cultura digital bastante arraigada, dispondo de informações variadas, mas, ao mesmo tempo,não parecem compartilhar da consciência da funcionalidade dos recursos digitais como instrumentos mediadores da comunicação diária. Essa condição dos estudantes fortalece a demanda por práticas de ensino diferenciadas, envolvendo o uso de tecnologias digitais disponíveis. Assim, entende-se que seja papel da escola criar condições para o uso dessas tecnologias em sala de aula, cabendo ao professor compreender como,quando e onde empregá-las.

Neste artigo, são compartilhadas algumas experiências em aulas de Língua Portuguesa (LP), ministradas no curso Técnico em Informática. Nessas experiências, são (i) explorados alguns padrões lógicos do sistema da língua, sem um trabalho exaustivo com a metalinguagem gramatical, e (ii) aproveitadas as facetas híbrida e dinâmica da cultura compartilhada pelos estudantes, atravessada por tecnologias digitais. Tais experiências são acionadas para contribuir mais diretamente com o perfil técnico esperado dos profissionais da informática.

O diferencial deste relato corresponde ao trabalho com elementos gramaticais a partir de jogos analógicos e digitais, elaborados com o intuito de ressignificar o estudoda língua portuguesa. Por fazerem parte do perfil de inúmeros profissionais da informática, produtores e consumidores de games, os jogos podem contribuir para deflagrar uma maior conscientização linguística, quando utilizados como artefatos mediadores no trabalho pedagógico com objetos de conhecimento.

Além da introdução, das considerações finais e das referências, este artigo está organizado em duas seções. A primeira dialoga com concepções teóricas da gramática, articulando-se com possibilidades metodológicas para uma aprendizagem ativa a partir de jogos analógicos e digitais. Já a segunda parte aborda a experiência com alunos do nível técnico de ensino, em atividades de gramática instaurada no contexto metodológico ativo e híbrido.

\section{Processos de apropriação de sistemas gramaticais}

O estudo sistematizado da gramática possibilita que os usuários da língua se conscientizem dos próprios conhecimentos linguísticos internalizados. Assim, passam a compreender mecanismos abstratos de forma mais concreta, são levados a pensar sobre a língua como objeto de investigação. Abordagens desse tipo também contribuem para divulgar os estudos linguísticos como campo de pesquisa científica, ampliando as representações sobre ciência compartilhadas pela sociedade.

É lamentável que muitos estudantes avancem ao longo dos anos escolares sem uma maior conscientização sobre os saberes linguísticos por eles compartilhados, chegando ao ponto de reproduzirem discursos equivocados de que não sabem a própria língua materna. Esses discursos podem ser reproduzidos pelo fato de os alunos confundirem a apreensão de saberes metalinguísticos, informados pela gramática normativa, com a própria competência de usuário da língua. Essa compreensão equivocada é corroborada pelo ensino transmissivo na escola regular, o qual tem se 
mostrado improdutivo para inúmeros alunos, especialmente para aqueles representantes dos estratos sociais menos favorecidos (cf. BAGNO, 2009).

Os indivíduos nascem com dotação biológica para a fala, mas, para a modalidade escrita da língua, há a necessidade do ensino e da inserção do usuário em situações de interação pela escrita. Isso pode ser constatado mesmo quando se observa crianças na tenra idade elaborando orações complexas, fazendo escolhas lexicais e gramaticais com alguma sofisticação. Essas crianças chegam, por vezes, a causar algum estranhamento nos próprios familiares.

O trabalho com a escrita parece mais propício ao desenvolvimento da consciência linguística dos alunos, pois, por meio dessa prática de linguagem, é possível visualizar o funcionamento da língua enquanto sistema. Martin e Rothery (2005), ao refletirem sobre a relação entre produção escrita e gramática, na perspectiva sistêmicofuncional, sugerem uma preocupação maior voltada ao processo de escrita, em vez do produto propriamente dito. Essa mudança de postura diante do trabalho sobre a língua leva a uma maior compreensão do funcionamento dos elementos gramaticais em contextos de uso.

$\mathrm{Na}$ escrita, a materialidade linguística se torna mais palpável para fins de estudo, na medida em que aproxima a gramática de possibilidades reais de significação. Ao produzir um texto, o aprendiz se depara com a escolha pela organização das orações, se escolhe a ordem direta ou indireta, marcando ou não o tema da oração; ele precisa decidir como organizar as relações coesivas entre orações, períodos e parágrafos; decide o foco em determinados assuntos, os vocábulos de retomada empregados. Além das escolhas gramaticais, há escolhas lexicais, considerando os efeitos de sentido que se deseja produzir ou garantir. Quer dizer, atuando em atividades linguísticas com e sobre a escrita é que o estudante poderá compreender o funcionamento da morfologia, da sintaxe e da semântica.

Uma mudança de paradigma do ensino de língua materna seria compreender que "a questão mais importante para a teoria gramatical é a seguinte: por que e como as expressões da língua naturais significam aquilo que significam" (FRANCHI,2006,p.53). Ou seja, ao ler e escrever, cabe sempre o pensar sobre a língua, buscando sistematizar as categorias linguísticas que os escritores ou usuários já possuem de forma interiorizada.

O estudo da gramática fora dessa perspectiva tem impactos consideráveis sobre o letramento ${ }^{2}$ do aluno e sobre as representações em torno da língua materna construídas por ele, pois além de distanciar a escola do mundo real, onde a língua é naturalmente dinâmica, também minimiza ou distorce as contribuições dos estudos linguísticos como mais uma mera disciplina escolar.

Em se tratando de língua, o estudo da gramática teria melhores resultados ao desenvolver a autonomia dos sujeitos, ao favorecer sua autoestima para utilizar a língua materna em diversas situações comunicativas, ao lhe acenar campos profissionais de atuação e ao possibilitar agir de forma mais crítica e consciente em práticas reais de leitura e escrita (cf. SILVA,2019).Assim, a educação lingüística em função de usosmais proveitosos da língua se apresenta como um modo de inclusão, especialmente de alunos menos favorecidos economicamente, em diversificadas situações de interação, orais, escritas ou multimodais, inclusive mediadas por tecnologias digitais.

Tendo em vista essa condição, é importante recorrer a uma metodologia de estudo da gramática mais produtiva, cujo foco incide-se sobre a funcionalidade em detrimento da memorização mecânica. Uma delas faz uso do que alguns pesquisadores

${ }^{2} \mathrm{O}$ termo letramento é compreendido como "habilidades de uso da escrita conforme demandado em diferentes domínios sociais, a exemplo do artístico, comercial, jornalístico e religioso, além do próprio domínio escolar". (SILVA, 2019, p.11). 
denominam atividade epilinguística, ou seja, a "prática que opera sobre a própria linguagem, compara as expressões, transforma-as, experimenta novos modos de construção canônicos ou não, brinca com a linguagem, investe as formas linguísticas de novas significações" (FRANCHI, 2006, p.97)

Nesse tipo de atividade, não há emprego da metalinguagem e a teoria gramatical é observada a partir da construção e reconstrução de textos, em operações concretas com orações, períodos ou parágrafos, testando possibilidades diversificadas de usos dos recursos linguísticos. O ideal é que a atividade epilinguística aconteça a partir da análise de textos diversos, já que nesses repousa o enfoque em situações reais, responsáveis pela apropriação de estruturas esquemáticas ou organizacionais dos textos e intencionalidades de diferentes gêneros da cultura escrita. As escolhas gramaticais e lexicais passam a ser exploradas respeitando as condições impostas por contextos de produção e circulação, incluído ainda convenções culturais (cf. SILVA, 2014). Em algum momento, os elementos linguísticos podem ser nomeados. Em outras palavras, metalinguagens podem ser empregadas, depois de uma "larga familiaridade com os fatos linguísticos"(FRANCHI, 2006, p. 98).Esse último enfoque denomina-se atividade metalinguística.

No embalo dessas aproximações com a teoria gramatical, é de grande validade considerar as contribuições das metodologias ativas, que ajudam a lidar com a individualidade dos aprendizados, com a motivação e a atenção dos estudantes. Esses conhecimentos atualmente estão em fase de apropriação e implementação em algumas escolas e instituições de ensino. Tais metodologias "estão centradas na participação efetiva dos estudantes na construção do processo de aprendizagem, de forma flexível, interligada e híbrida" (MORAN, 2018,p.4). O trabalho com jogos, por exemplo, alinhase a essas metodologias pelo protagonismo discente possibilitado no ato de aprender.

Os jogos e as aulas roteirizadas com a linguagem de jogos (gamificação) estão cada vez mais presentes na escola e são estratégias importantes de encantamento e motivação para uma aprendizagem mais rápida e próxima da vida real. Os jogos mais interessantes ajudam os estudantes ao enfrentar desafios, fases, dificuldades, a lidar com fracassos e correr riscos com segurança (MORAN, 2018,p. 21, grifo do original)

Umas das maiores contribuições da aprendizagem baseada em jogos é que os alunos aprendem fazendo, observando seu próprio percurso e avaliando seu potencial em tempo real, seja no coletivo ou no individual. No caso dos jogos digitais, muitos estudantes conseguem ver na tela do smartphone ou do computador os erros e os acertos cometidos, a nota alcançada, podendo refazer as atividades em seu próprio ritmo, permitindo um maior acompanhamento por parte do professor.

Nem todas as escolas estão preparadas em termos de recursos tecnológicos, de modo a promover atividades on-line com jogos. Todavia, para aquelas que não dispõem de ferramentas assim, é possível integrar tecnologias mínimas ou mesmo empregar jogos a partir de materiais concretos, produzidos com materiais recicláveis ou de papelaria. Estes últimos podem ser igualmente estimulantes, se não forem executados de forma mecânica (cf. MORAN,2015), uma vez que a produtividade pedagógica não se limita ao mero emprego das tecnologias, é importante se atentar para um uso proveitoso das tecnologias. Em relação ao ensino de gramática, os jogos podem contribuir significativamente para minimizar os impactos de algumas abstrações características de sua organização. 
Quando trabalhadas nessa perspectiva, as atividades gramaticais criam ambientes propícios para a aprendizagem, rompendo com um ensino vertical, no qual o conhecimento legitimado e os aprendizes se encontram. $\mathrm{O}$ mais importante com isso é que o cenário pedagógico, em particular o das aulas de LP, possa se caracterizar como um laboratório em que todos estão imbuídos em alguma atividade de ação-reflexão-ação com e sobre a linguagem.

A articulação dos jogos como atividades analógicas e digitais se integram ao chamado ensino híbrido. Conforme Bacich, Tanzi Neto e Trevisani, (2015, p. 51), "a expressão ensino híbrido está enraizada em uma ideia de educação híbrida, em que não existe uma forma única de aprender e na qual a aprendizagem é um processo contínuo, que ocorre de diferentes formas, em diferentes espaços" (grifo do original). Outra alternativa trazida pelo ensino híbrido é a garantia do protagonismo estudantil, voltada para a construção do conhecimento e em oposição ao ensino focado na transmissão mecânica de saberes. A problematização dessa concepção de educação não surge com o ensino híbrido, pois já havia sido questionada por diversos educadores ao longo da história da educação. De fato, essa questão tem ganhado mais força por conta de uma maior disponibilização e acesso à informação, provocadas pela expansão das tecnologias digitais móveis. Atualmente, a escola, o professor, a biblioteca e os livros não são mais as únicas fontes de informação. Por isso, não faz mais sentido o professor insistir na mera transmissão de informações.

Na obra Comunicação ou Extensão? Freire (1977), utilizando-se da metáfora do agrônomo educador e dos camponeses, questiona as práticas conteudistas desses profissionais quando esses apenas transmitem seu saber técnico. Tal atividade é denominada por Freire de extensão, sendo pautado na mera transmissão, na antidialogia e, portanto, distante do que se considera educação libertadora. Para o autor, a relação entre esses grupos deveria ocorrer a partir da comunicação com os sujeitos, problematizando e negociando os conhecimentos, refletindo acerca dos saberes adquiridos.

No contexto do estudo da gramática, o diálogo entre professores e alunos se daria melhor em atividades de reflexão sobre a língua, em que os aprendizes tivessem oportunidades de aprender fazendo, em atividades híbridas. O professor, por sua vez, atuaria como curador, mediando as reflexões com os estudantes de modo a favorecer uma maior conscientização sobre a língua.

\section{Contextualizando a sala de aula}

Para exemplificar como se deu a aplicação do ensino híbrido, são ilustradas algumas atividades práticas em que a abordagem epilinguística foi utilizada, desdobrando-se em jogos, tanto em contexto on-line como off-line. Conforme dito na introdução deste artigo, as experiências retratadas aconteceram em turmas do curso Técnico em Informática, ofertado pelo Instituto Federal do Tocantins(IFTO), no Câmpus Avançado Lagoa da Confusão, em aulas da disciplina Comunicação Linguística (CL).

O módulo inicial desse curso prepara o aluno para se tornar um Operador de Computador. Também integram esse módulo as seguintes disciplinas: Informática Básica; Lógica de Programação;Fundamentos de Informática; e Introdução à Redes de Computadores. Visam ajudar o aprendiz a se apropriar das tecnologias do computador de uma forma mais complexa que o habitual, tornando-se habilitados a compreender as interfaces e as estruturas operacionais de tal máquina.

Considerando a oferta noturna e as modalidades concomitante e subsequente ao Ensino Médio, o estudo da língua materna pode aparentar alguma desvantagem em 
relação à predominância de disciplinas técnicas. Esse contexto justifica o esforço por tornar as aulas de CL dinâmicas, motivadoras e úteis aos alunos. De algum modo, busca-se realçar a funcionalidade da disciplina, o que passa pelo esforço de articulação com outros componentes curriculares. Para tanto, a observação dos alunos e o diálogo com os professores especialistas têm contribuído para a construção de uma abordagem pedagógica diferenciada nas aulas de CL.

Faz-se necessário apropriar-se de ferramentas tecnológicas usadas no curso, já que se configura como um contexto de formação diferenciado quando comparado a outras escolas de curso regular. Lima e Moura (2015, p.91), ao destacar o papel do professor nesse novo cenário educacional marcado pelas tecnologias digitais, concebem o referido profissional como um arquiteto do conhecimento, precisando investir na própria formação e ampliando os horizontes. A partir de reflexões como essas, a proposição de exercícios de transmissão de conteúdo é cada vez menor e o investimento em atividades realizadas com e para os alunos de modo prático e dinâmico torna-se rotineiro.

Os objetos de conhecimento foram contemplados nas aulas, ainda que tenham sido redimensionados. Considerando que a instituição disponibiliza a plataforma adaptativa Moodle $^{3}$, são postados textos e materiais de leitura, previamente, aos estudantes. Em sala de aula, o tempo fica reservado para a problematização e a reflexão sobre aspectos da gramática do português em textos, incluindo atividades de produção escrita orientadas.

Ao focalizar questões textuais, o trabalho com a gramática se mostrou fértil no Técnico em Informática. As reflexões possibilitadas pelo estudo do sistema da língua desencadeiam pontos de contato expressivos no estudo das linguagens de programação, haja vista que também possuem uma sintaxe e uma semântica ${ }^{4}$. Quando o aluno não consegue refletir sobre os esquemas organizacionais da própria língua materna, torna-se difícil abstrair outros sistemas,incluindo aí as linguagens de programação.

Algumas atividades epilinguísticas em formato de jogos, on-line ou off-line, buscaram explorar questões de estrutura, organização sintática e produção de sentidos. A intenção dessas atividades também foi contribuir para o aprendizado de outros sistemas semióticos, como é o caso das linguagens de construção de interfaces do computador.

De posse desse contexto, relata-se o trabalho da professora ${ }^{5}$ com esses jogos, fazendo um exercício de reflexão sobre os procedimentos metodológicos empreendidos. Propõe-se analisar a funcionalidade dos jogos para a reflexão linguística, seus usos, potencialidades e objetivos, não deixando de avaliar as fragilidades das atividades propostas. Como se sabe, toda ação pedagógica é passível de ajustes. Para tanto, faz-se necessário que o professor se disponha a olhar criticamente sobre a própria prática profissional a fim de aprimorá-la.

\footnotetext{
${ }^{3} \mathrm{O}$ Moodle possui vários recursos que oferecem flexibilidade na construção de atividades, porém insuficientes para a elaboração de jogos complexos. Em contrapartida, disponibiliza um repositório de plugins que expandem suas funcionalidades. Assim, é possível encontrar plugins focados em gamificação. Profissionais da área de tecnologia da informação podem criar seus próprios plugins, ampliando essas possibilidades.

${ }^{4}$ A semântica refere-se ao significado do código enquanto a sintaxe refere-se a forma de codificar.

${ }^{5}$ Optou-se por empregar o gênero feminino para o substantivo professora em referência à profissional, primeira autora deste artigo, que desenvolveu e aplicou a experiência relatada.
} 


\subsection{Experiências de análise linguística}

A experiência aqui compartilhada integra um percurso ou trilha de atividades, não podendo essa ser concebida como ação isolada dentro da disciplina. As propostas relatadas ocorreram a partir das produções escritas desenvolvidas pelos estudantes, ou seja, serviram para problematizar textos escritos por eles. Por sua vez, os jogos surgem da necessidade de propor um maior engajamento pelo estudo da língua, distanciando-se de uma abordagem informada pela prática de transmissão de conteúdos disciplinares pouco estimuladora. A Figura 1 sintetiza e ilustra o percurso proposto.

Figura 1: Percurso da experiência pedagógica
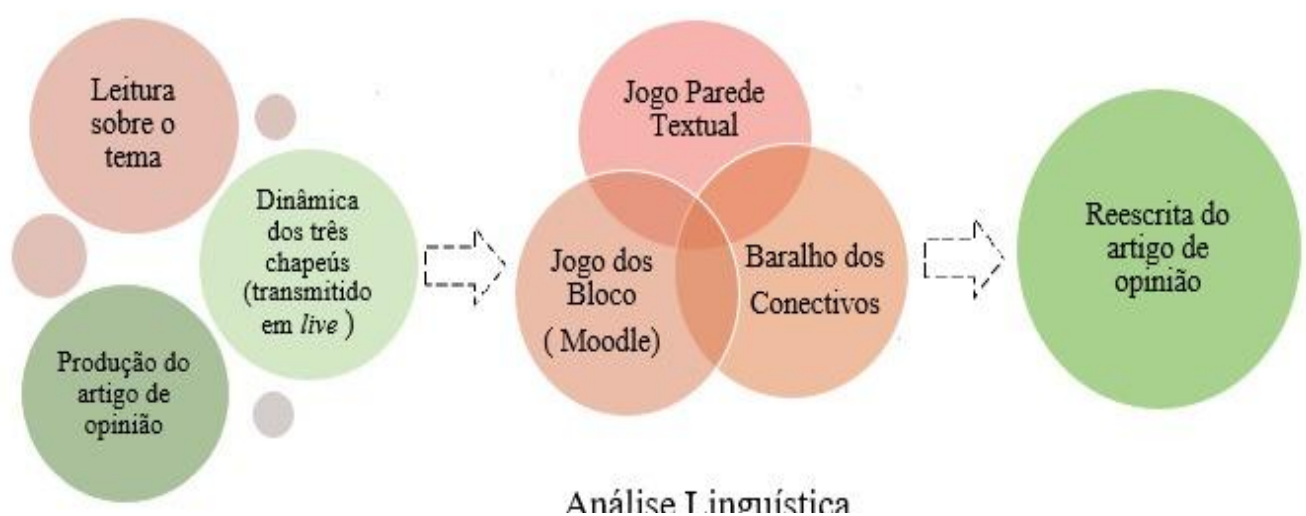

Análise I inouística

Fonte autoria própria

Como mostra a ilustração, os alunos foram inseridos em um contexto de produção escrita, começando pela apropriação de um tema escolhido, que ocorreu por meio da leitura de reportagens, notícias e artigos de opinião. Este último abordou a segurança na internet, temática explorada pelo professor de Fundamentos de Informática e, portanto, próxima do universo dos estudantes. Com isso, foram estabelecidos a interação e o diálogo a partir desse exercício de leitura. Na sequência, houve um debate oral transmitido em forma de live, que contou com a aplicação metodologia ativa denominada Seis Chapéus ${ }^{6}$, uma estratégia pedagógica em que os alunos leem textos e debatem o tema, respeitando uma ordem definida por chapéus coloridos.

A intenção de usar a metodologia descrita foi a de organizar o debate, pois as cores desses chapéus servem para guiar a argumentação. Os alunos perceberamque, no gênero artigo de opinião, é preciso expor dados gerais da matéria, argumentar com opiniões contrárias e favoráveis, realizar apontamentos que desdobrem em possíveis soluções.

A etapa relatada antecedeu a produção escrita, preparando o aluno para familiarizar-se com a temática e com o gênero artigo de opinião. Para ajudar na sistematização das ideias, realizou-se um planejamento coletivo com os estudantes e, à medida que produziam, acompanhou-se o trabalho, tanto de forma individual como

\footnotetext{
${ }^{6}$ Essa dinâmica envolve a divisão da turma em seis grupos com cores diferentes (branco, amarelo, preto, verde, vermelho e azul). Cada integrante faz uso de um chapéu, cuja a simbologia da cor é que define o papel do grupo na discussão. Por exemplo: o amarelo remete a pontos positivos, o preto a negativo, o verde a solução de um problema... Nos termos de Alcântara (2020, p. 99), esse tipo de dinâmica "é uma boa estratégia para tomada de decisões, análises de situações, principalmente as mais complexas, gerando uma decisão consistente".
} 
coletiva. Ao fim dessa atividade,foi possível analisar alguns problemas na escrita, atrelados preponderantemente a aspectos sintáticos, como mostra o Exemplo 1.

Exemplo 1: Excerto do texto do aluno

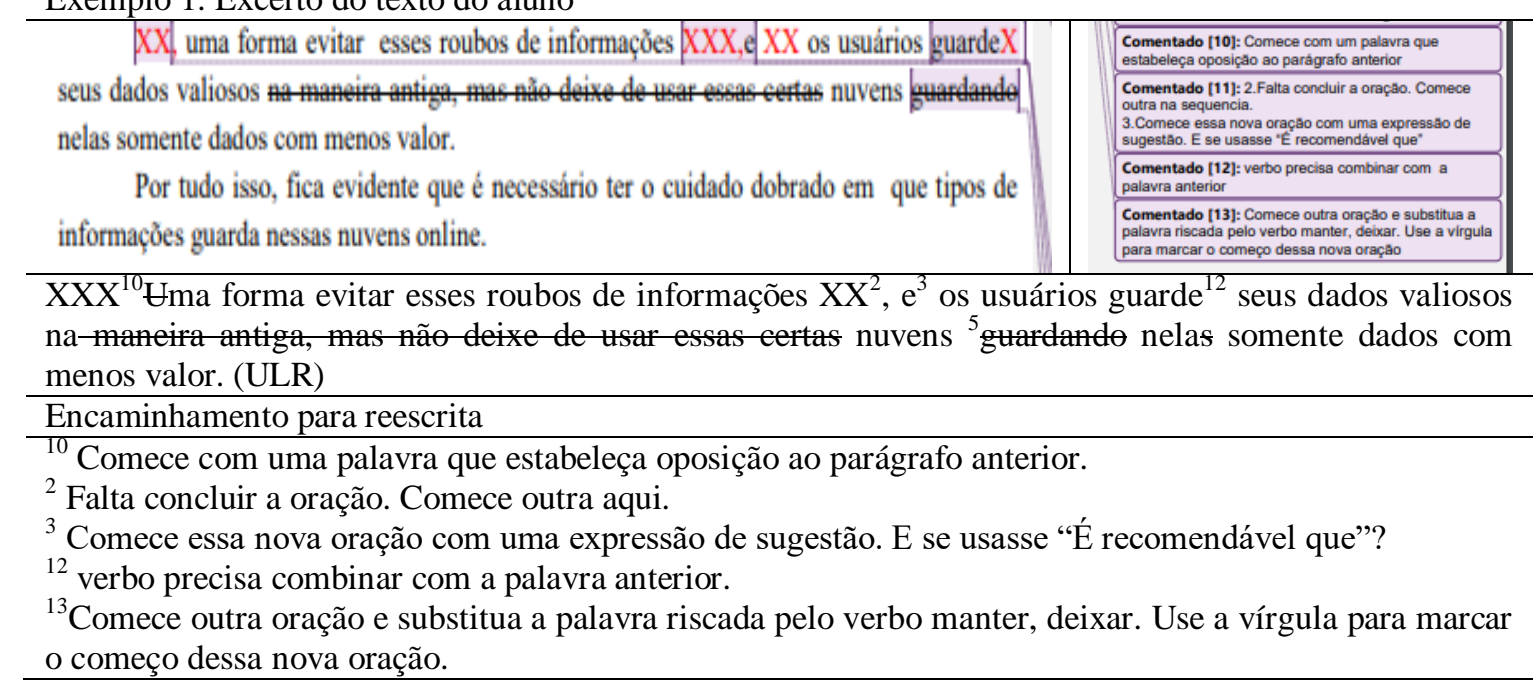

No excerto do Exemplo $1^{7}$, verifica-se algumas sugestões de reescrita apontadas pela professora sobre a primeira versão do texto do aluno, identificado pelas iniciais maiúsculas do nome. Essas orientações incidem sobre questões textuais e ainda sobre questões relacionadas à estrutura da língua. Há sugestões voltadas para a exclusão ou a substituição de palavras, acréscimos de articuladores, sinais de pontuação. Nesse primeiro momento, evita-se empregar muita metalinguagem, pois foi feito esforço para se alinhar ao que se compreende por atividade epilinguística.

Considerando as dificuldades dos estudantes em organizar os parágrafos e elaborar construções sintáticas claras, envolvendo o emprego da pontuação, a professora decidiu trabalhar alguns níveis de organização de constituintes linguísticos (parágrafo, período, oração, palavras). Só que havia o propósito de fazer isso de maneira dinâmica e, até mesmo, palpável para os alunos, minimizando a abstração atrelada a esse tipo de abordagem. Com isso, após ler todos os textos da turma e sugerir as adequações, foi selecionado um exemplar, ampliado a grafia, feita a impressão em folhas coloridas e recortados os termos que representavam os constituintes das orações. O Exemplo 2 ilustra parcialmente a dinâmica da atividade.

\footnotetext{
${ }^{7}$ As correções no Google Docs permitem inserções de comentários na lateral da página, facilitando o processo de encaminhamento da reescrita. Com elas é possível resgatar o histórico da produção, permitindo um acompanhamento por parte da professora e do aluno. Devido à limitação espacial, a título de ilustração, foi reproduzida aqui apenas um parágrafo do texto selecionado. Salienta-se ainda que o autor do exemplo focalizado não realizou a rescrita conforme orientado, diferentemente de outros alunos que seguiram o comando de reescrita, apresentado pela professora.
} 


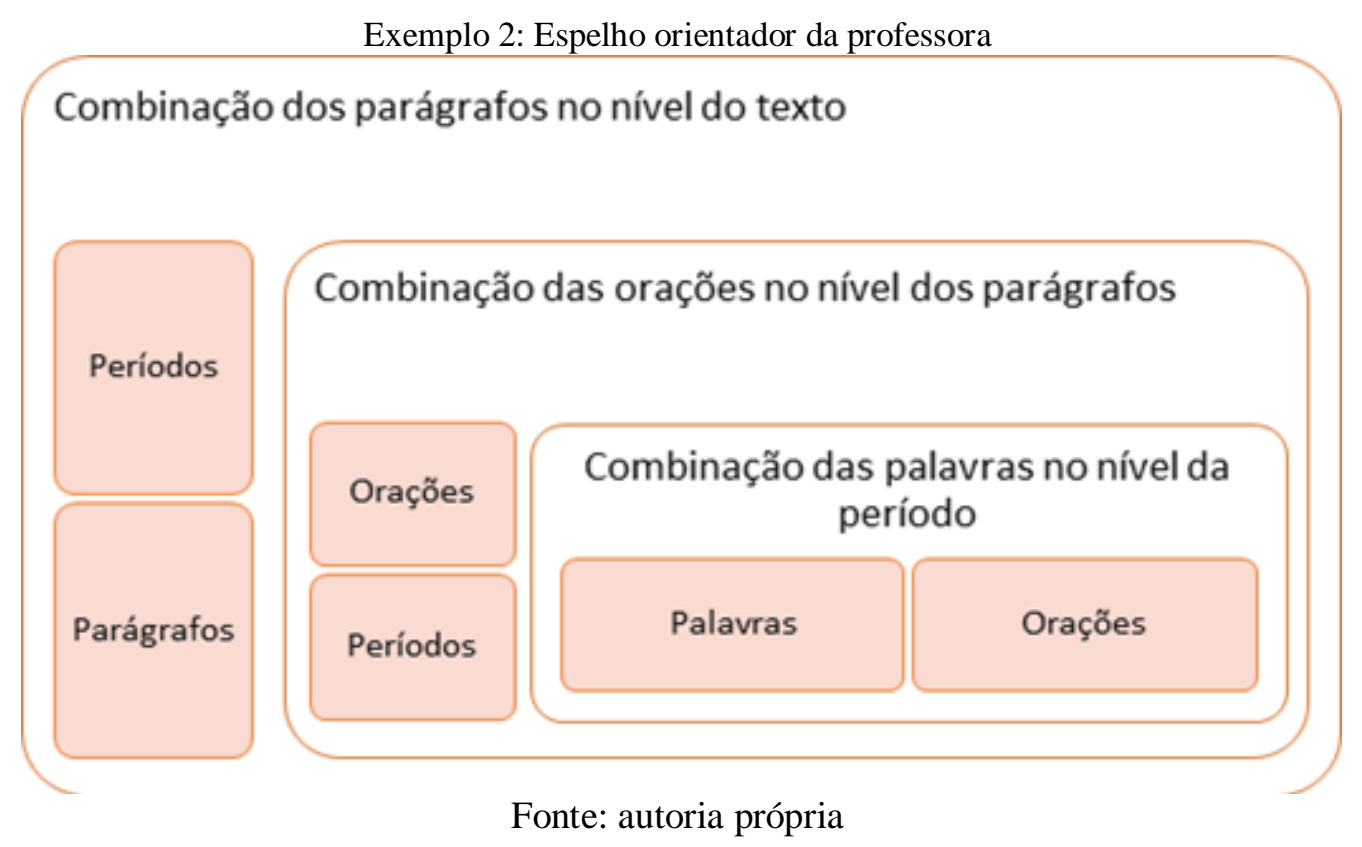

O desafio dos estudantes era organizar os constituintes das orações, que foram distribuídos às duplas e aos trios, respeitando a lógica representada na imagem. Para que todos percebessem os níveis de organização textual, os parágrafos foram marcados por diferentes cores (amarelo, verde, azul, rosa). À medida que iam refletindo sobre as diversas combinações sintáticas, a professora passava por todos os grupos e questionava o porquê de cada escolha, buscando explorar a autorreflexão do estudante sobre a língua. Com isso, não foram empregadas nomenclaturas gramaticais, permitindo que os estudantes refletissem sobre o funcionamento da língua a partir dos usos.

Figura 2: Estudantes trabalhando no jogo

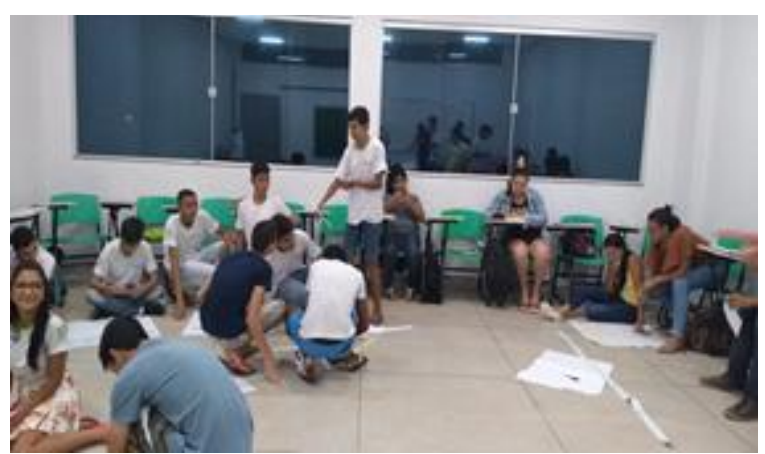

Figura 3: Estudantes organizando os períodos

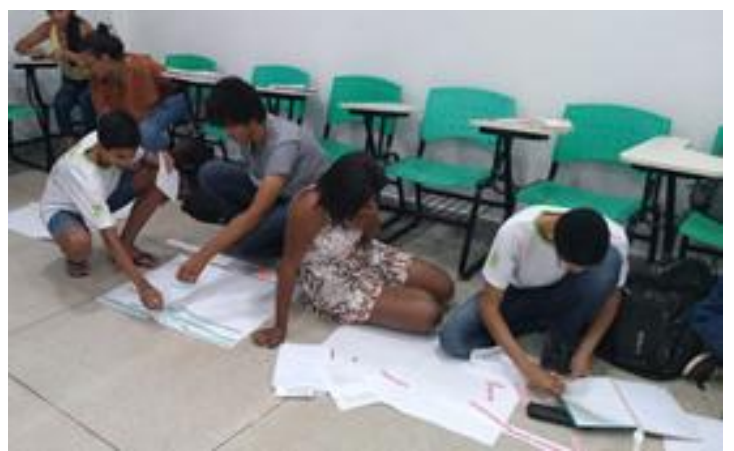

Fonte: arquivo pessoal da professora

Ressalta-se que a atividade está organizada em níveis, representando a própria organização linguística. Diante disso, não bastava montar a oração, era necessário organizá-la dentro dos períodos, dentro dos parágrafos e, por fim, dentro do texto. Todo esse esquema ocorreu de modo gradual, sem tropeços, com reflexões alternadas entre os diferentes níveis, favorecendo diferentes trocas.

No primeiro nível, os alunos foram orientados a montar os períodos com as palavras e constituintes soltos, conforme ilustrado nas Figuras 2 e 3. No segundo nível, os alunos deveriam montar os parágrafos, guiando-se sempre por períodos de igual cor. Essa recomposição ainda permitia uma maior reflexão sobre a ordem do parágrafo, 
respeitando não apenas a lógica sintática, mas a significação. Nesta experiência, foram montados quatro parágrafos, que deveriam estar organizados em forma de texto.

No último nível, os grupos liam os parágrafos para toda a turma e, respeitando as lógicas da sintaxe e da significação, analisavam quais parágrafos mais se adequavam como introdução, desenvolvimento e conclusão do artigo de opinião. O texto construído foi colado na parede da sala, daí o jogo a ser chamado de Parede Textual.

As equipes que apresentavam corretamente as combinações recebiam pequenos brindes, que variavam conforme os níveis relatados acima. A intenção era incentivar o esforço e engajar as discussões sobre o processo de construção textual. Por meio dessa atividade de conscientização sobre a organização de elementos linguísticos, considerando diferentes níveis de organização, foi possível tocar na materialidade linguística, compreender e explicitar a lógica subjacente à organização textual.

Certamente, refletir sobre os sistemas linguísticos em sua materialidade textual pode levar os estudantes a exercitarem melhor o raciocínio para abstrações mais complexas que a área da computação demanda. Na verdade, a disciplina de Lógica de Programação é a que mais reprova em cursos Técnicos de Informática e uma das queixas por parte dos alunos é o elevado nível de abstração. A atividade proposta ainda possibilita alguma alfabetização científica dos alunos, oferecendo-lhes oportunidades de se verem em condições de agir com a língua em diferentes contextos sociais, experienciarem a prática de refletir sobre ou analisar o funcionamento da língua (cf. SILVA, 2019; 2020).

Depois dessa etapa, os alunos interagiram com desafios semelhantes ao da Parede Textual, só que por meio da plataforma adaptativa Moodle, conforme ilustrado no Exemplo 3. Entre as propostas, os estudantes brincaram com jogos simples de mover palavras, constituintes e orações, até chegar ao texto. O sistema Moodle pontuava os acertos e mostrava aos aprendizes os equívocos cometidos, oferecendo-lhes um feedback imediato.

Exemplo 3: Página do jogo dos blocos no Moodle

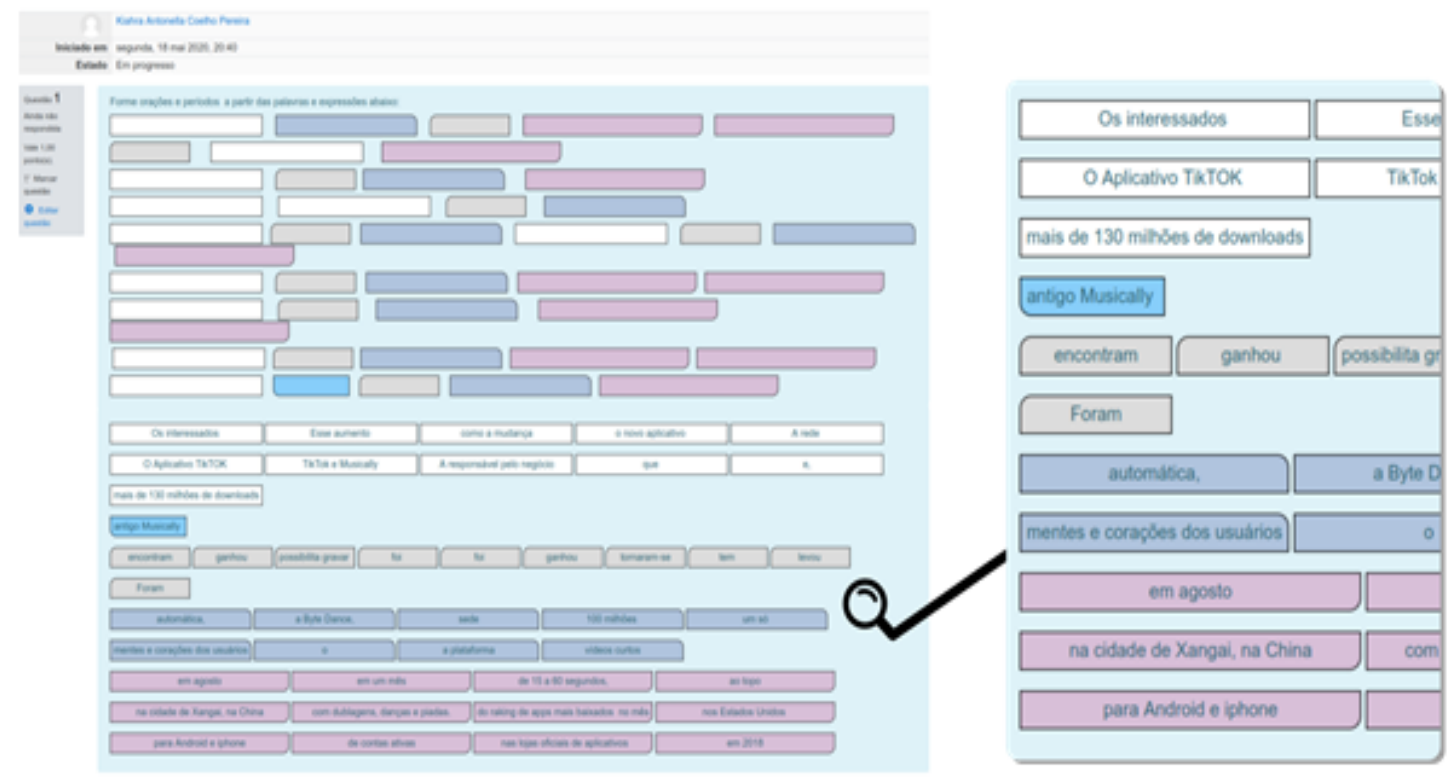

Fonte: Plataforma Moodle

O critério linguístico de separação dos elementos respeitou os constituintes básicos do sistema da língua: sujeito, verbo, objetos e complementos, marcados respectivamente pelas cores branca, azul, cinza e rosa, padronizadas pelo próprio 
Moodle. A proposta era reforçar essa organização da língua, formada por categorias funcionais nas quais as orações se baseiam para formar parágrafos e, consequentemente, formar textos.

Como se pode notar, todas as terminologias gramaticais estão subentendidas, guiando os estudantes pelas cores, as quais precisam ser utilizadas com bastante critério na produção de jogos. Nesse jogo inicial, os alunos movem apenas os constituintes, encaixando-os corretamente nos blocos superiores. É a metáfora da construção de uma parede, elaborada propositalmente para que os estudantes refletissem sobre o processo de escrita na perspectiva gramatical.

O Exemplo 4 exemplifica a segunda fase do jogo, que consiste em desembaralhar períodos e parágrafos, refletindo sobre a organização do texto. Por meio desse jogo simples, os alunos escolhem, entre as opções apresentadas, qual a ordem para melhor construir o texto, respeitando tanto a lógica da sintaxe como também da significação.

$$
\text { Exemplo 4: Segunda fase do jogo no Moodle }
$$

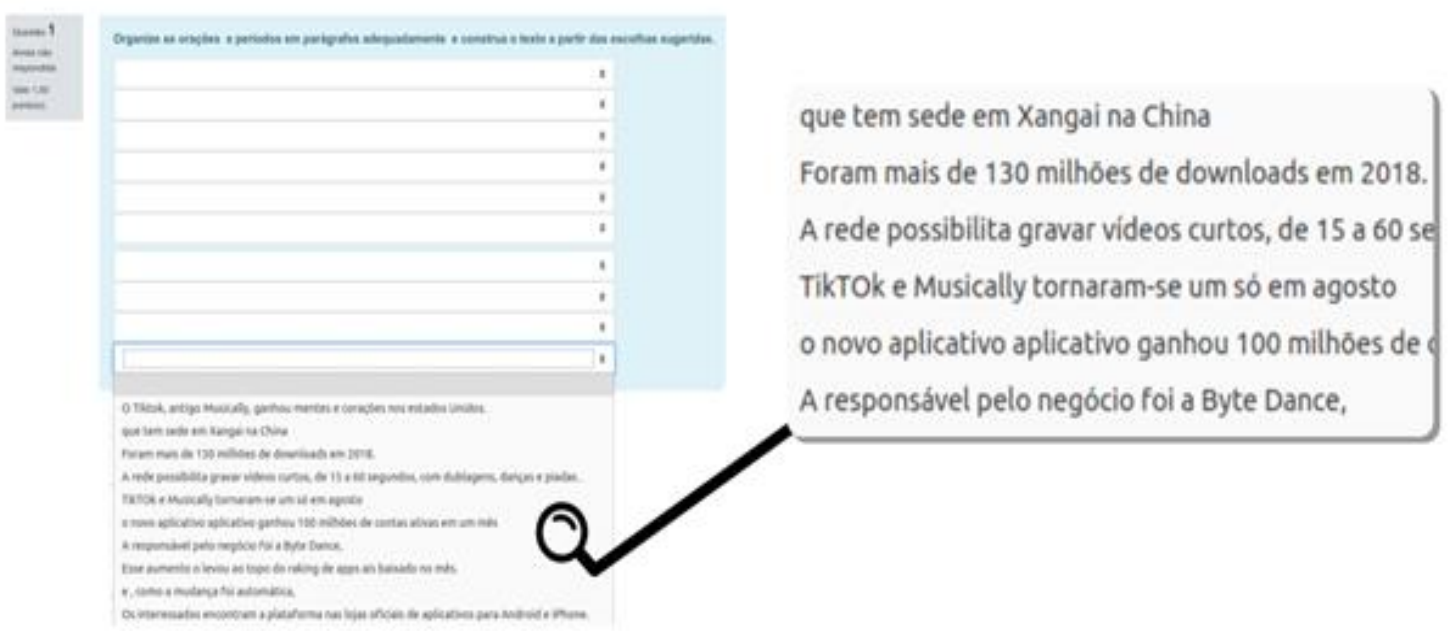

Fonte: Plataforma Moodle

As propostas de jogos relatadas são simples, por não dispor de recursos como uma narração de fundo, recompensas, elementos mais sofisticados que fogem da capacidade técnica do sistema. Ao refletir sobre possíveis adaptações, a inclusão desses itens citados seria um dos primeiros pontos a se incrementar, juntamente com um sistema de pontos que bonificaria os jogadores de acordo com as respostas: algumas valendo mais, outras valendo menos. Além disso, seria possível desenvolver uma interface mais amigável e com feedback imediato para cada resposta, incluindo aí animações para o recebimento de pontos e elogios.

Para que essas melhorias pudessem vir a ocorrer, um profissional da área de tecnologia desenvolveria um plugin específico para a plataforma adaptativa Moodle, que por ser gratuita, apresenta limitações de recursos. Com isso, exige-se conhecimentos técnicos maiores por parte dos professores ao elaborar propostas mais sofisticadas, o que, certamente, não é da competência dos professores de LP. Os jogos elaborados pela professora são atípicos, uma vez que partem de motivação pessoal em implementar o ensino híbrido nas aulas de CL

Após todo esse trabalho de reflexão acerca do sistema de organização da língua, os alunos finalmente puderam reescrever os artigos de opinião, buscando respeitar tanto o sistema linguístico como os sentidos produzidos. A partir da experiência aqui compartilhada, relata-se a articulação entre diferentes eixos de práticas escolares de linguagem - Leitura, Oralidade, Escrita e Análise Linguística -, conforme planejamento 
proposto em diretrizes oficiais para o ensino de LP (cf. BRASIL, 1998; 2018). Paralelamente, foi introduzido o trabalho com algumas nomenclaturas gramaticais familiaresaos alunos por meio de atividades formais e outros jogos, como Palavras Cruzadas, também disponível no Moodle.

Exemplo 5: Esquema do jogo de baralho
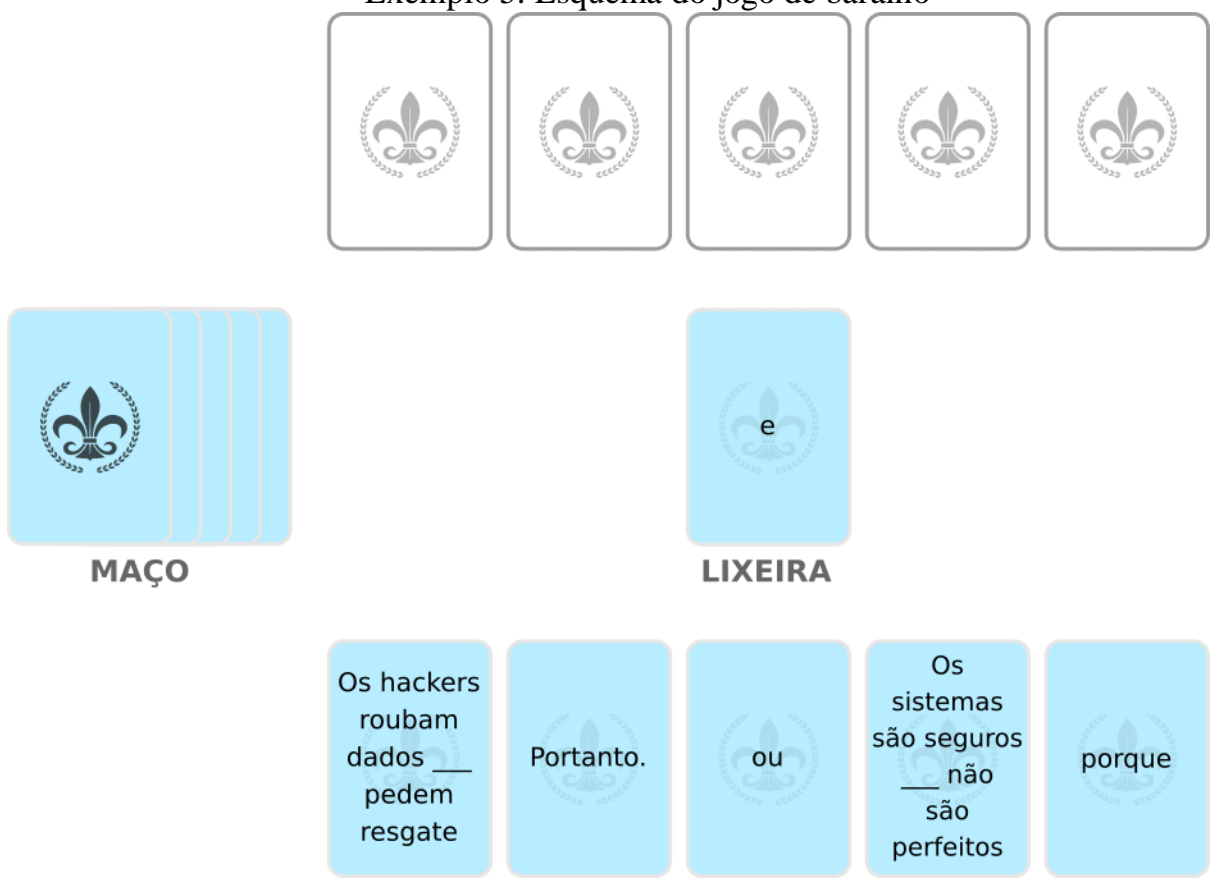

Fonte: autoria própria

Durante esse percurso, ainda foi possível implementar outro jogo com estruturas sintáticas da língua, para atender a uma dificuldade notada pela professora durante o processo de reescrita dos textos: os usos de articuladores textuais. Muitos estudantes não estavam fazendo uso dos conectivos, tanto no nível microtextual, entre orações, como no nível intermediário do texto, entre parágrafos. Em vista disso, foram selecionados alguns excertos das produções dos próprios discentes e outros textos, como manchetes de jornais e revistas, além de elaborado o Baralho dos Conectivos, ilustrado no Exemplo 5.

Nesse jogo, dois ou mais participantes recebem seis cartas, de um total de 52 (cinquenta e duas), em que algumas contêm orações e outras, articuladores argumentativos. A missão dos jogadores é formar três pares de cartas (sendo cada par formado por uma primeira com oração gramatical e articulador omitido e uma segunda com um conectivo), de modo que seja estabelecida uma relação semântica harmoniosa entre a oração e o articulador para cada par. O jogo funciona em rodadas: ao receber as cartas, um primeiro jogador compra uma carta do maço, tenta formar os pares e se, possível, bater, ao formar os três pares. As cartas excluídas pelos jogadores vão para a lixeira, ficando visível aos demais, em caso de alguém querer utilizar. Quando o jogador descarta uma carta, a vez é passada ao jogador seguinte, seguindo o sentido horário. O jogador seguinte poderá comprar do maço ou comprar a última carta descartada na lixeira. A partida pode terminar quando alguém bate, ou seja, forma os três pares, ou ainda quando restar apenas um jogador que não conseguiu reunir as cartas necessárias. 
Figura 7: Alunos interagindo com o jogo

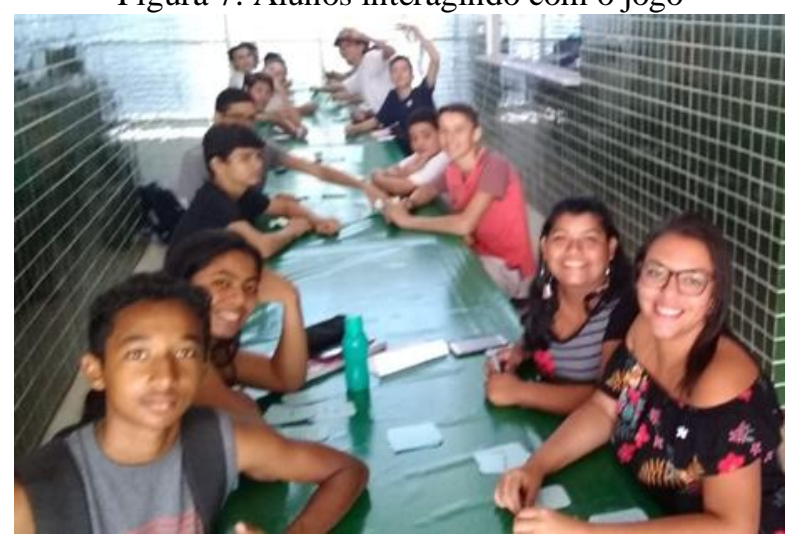

Fonte: arquivo pessoal da professora

Vale destacar que esse jogo é totalmente intuitivo, condicionado à compreensão das orações gramaticais, já que não está amarrado a nomenclaturas gramaticais. A preocupação inicial é que o aluno reflita sobre os usos dos articuladores e os sentidos que eles estabelecem nos trechos e textos selecionados. Após esse primeiro contato, a metalinguagem gramatical pode ser explorada, até mesmo como forma de facilitar a comunicação sobre os fatos linguísticos apresentados durante as orientações com a reescrita, por exemplo. Depois do jogo, outros exercícios via Moodle complementam o processo de apropriação do objeto de conhecimento.

Em relação à avaliação, que é uma preocupação de professores e alunos, é possível acompanhar o rendimento dos alunos, durante a sequência de atividades. No caso em particular do componente curricular aqui focalizado, optou-se por não realizar avaliações formais ao fim de cada bimestre. O próprio conjunto de atividades foi suficiente para traçar o rendimento dos estudantes. Somado a isso, a plataforma Moodle disponibiliza um feedback ${ }^{8}$ imediato aos estudantes, ao fim de cada jogo, disponibilizando esse registro individualmente ao aluno e ao professor.

Por tudo isso, fica claro que qualquer atividade baseada em jogos, como as que foram compartilhadas neste artigo, por mais simples que possam parecer, tem muito a contribuir com a educação. Ao longo dessa prática, percebeu-se que a aprendizagem ativa e híbrida envolve os estudantes, amplia a participação deles no próprio processo de aprendizado, tornando-os mais autônomos, disciplinados, críticos e conscientes em relação à construção do saber, especialmente aqui o saber linguístico.

\section{Considerações finais}

Ao apresentar algumas abordagens sobre o estudo da gramática e compartilhar experiências enfocando o trabalho com a linguagem em uma perspectiva mais produtiva, o interesse foi o de mostrar aos estudantes o quanto eles, sem se darem conta, ignoram o conhecimento linguístico que possuem acerca do sistema do português. Os jogos citados, tanto on-line quanto off-line, buscaram promover uma conscientização linguística dos aprendizes, privilegiando uma aprendizagem ativa em detrimento do ensino transmissivo de conteúdos gramaticais e de práticas de leitura e escrita excessivamente escolarizadas.

Em todas as atividades relatadas, percebe-se que a professora se orientou, conscientemente ou não, pela abordagem da educação científica, ao refletir sobre a própria prática profissional e buscar inovações,e ao propor atividades de análise

\footnotetext{
${ }^{8}$ Ao cadastrar jogos e outras atividades no Moodle, o professor seleciona critérios de avaliação, que os alunos têm acesso, de forma imediata e individual, mediante conclusão do planejado.
} 
linguística. Por meio dessas, os alunos tiveram oportunidade de operar concretamente sobre os fenômenos da língua, mobilizando-os, organizando-os da melhor forma mediante problematizações. Pensarsobre a língua desse modo oferece uma compreensão mais abrangente das habilidades de leitura, escrita, compreensão textual, saberes que se desdobram para além do espaço escolar.

$\mathrm{O}$ esforço engendrado pela professora corresponde ao esforço para mudar a própria rotina escolar, na medida em que a intenção das práticasdes envolvidas era construir conhecimentos, engajar jovens desmotivados a verem algumas funcionalidades da língua. Esse exercício consciente da professora pode repercutir muito mais no contexto de uma área técnica, em que profissionais da informática, bacharéis sem licenciatura,atuam como docentes, alguns, certamente, sem nunca terem idealizado se tornarem professores quando optaram pelo curso superior, diante de exames vestibulares ${ }^{9}$.

As estratégias desenvolvidas e relatadas têm margem para aprimoramentos do ponto de vista tecnológico, e também pedagógico, como é de praxe nas diversas situações em que o professor atua em sala de aula. Por hora, segue a confiança de que se contribuiu com os estudantes, especialmente depois de ler depoimentos em grupos de WhatsApp da turma, em que muitos se mostraram satisfeitos com o percurso percorrido e os saberes adquiridos. Certamente, isso é o maior ganho para a professora, que esperava dos aprendizes a autorreflexão a partir de saberes internalizados. Consequentemente, os depoimentos também serviram para confirmaro êxito das escolhas e do percurso metodológico trilhado.

Por fim, espera-se ainda motivar outros professores, que se deparam diariamente com o desafio de estabelecer aproximações entreconhecimentos científicose estudantes. Deseja-se que processos desafiadores possam ser assumidos, sendo uma preocupação primeira dos profissionais da educação pensar no aluno, refletirna esobre a própria prática. Assim, pode-se desenvolver competências não apenas escolares, mas dee para a vidacom os estudantes nos mais diferentes níveis de formação.

\section{Referências}

ALCÂNTARA, E.F.S.(Org) Inovação e renovação acadêmica: guia prático de metodologias ativas. Volta Redonda, FERP,2020, p. 99-101.

BACICH,L.;NETO TANZI, A; TREVISANI, F.M.(Org.). Ensino Híbrido: personalização e Tecnologia na educação.In: BACICH, L; NETO TANZI, A.; TREVISANI, F. M. (Org.). Ensino Híbrido: personalização e Tecnologia na educação. Porto Alegre: Penso, 2015, p. 47-65.

BAGNO, M. Os objetos do ensino de língua na escola: uma mudança de foco. In: COELHO, L. M. (Org.). Lingua materna nas séries iniciais do Ensino Fundamental: de concepções e de suas práticas. Petrópolis: Vozes, 2009. p. 157-171.

BRASIL. Base Nacional Comum Curricular. Brasília: MEC, 2018.

BRASIL. Parâmetros Curriculares Nacionais: Língua Portuguesa. Brasília: Secretaria de Educação Fundamental, 1999.

\footnotetext{
${ }^{9}$ No campus que a professora atua apenas ela é licenciada pois a maioria dos docentes são analistas de sistemas, cientistas da computação, engenheiros agrônomos e químicos.
} 
FRANCHI, C. Criatividade e Gramática. In: POSSENTI,S. (Org.). Mas o que é mesmo "gramática?". São Paulo: Parábola Editorial,2006.

FREIRE, P. Extensão ou comunicação? 11 ed. Rio de Janeiro: Paz \& Terra, 1977.

LIMA, L. H. F.; MORA, F. R. O professor no ensino híbrido. In: BACICH,L; NETO TANZI, A.; TREVISANI, F. M. (Org.).Ensino Híbrido: personalização e Tecnologia na educação. Porto Alegre: Penso, 2015, p. 89-102.

MORAN,J. metodologia ativas para uma aprendizagem mais profundas. In: BACICH, L.; MORAN,J.(Org.). Metodologias ativas para uma educação inovadora: uma abordagem teórico-prática.Porto Alegre: Penso, 2018, p. 1-25.

MORAN,J. Educação Híbrida: um conceito-chave para a educação, hoje. In: BACICH,L.; NETO TANZI, A.; TREVISANI, F.M.(Org.).Ensino Híbrido: personalização e Tecnologia na educação. Porto Alegre: Penso,2015, p. 28-45.

MARTIN,J.R; ROTHERY, J.The Ontogenesis of Written Genre.In: ZHENHUA, W. (Ed.). Language in Education: Collected Works of J.R. Martin, Volume 7. Shanghai: Shanghai Jiao Tong University Press, 2012. p. 08-59.

SILVA, W. R. Considerações sobre contexto de cultura na Linguística SistêmicoFuncional. In: XVII Congresso Internacional da Associação de Linguística e Filologia da América Latina - ALFAL. João Pessoa: Idéia, 2014. p. 1991-2003.

Educação científica como abordagem pedagógica e investigativa de resistência.

Palmas: Universidade Federal do Tocantins, 2020.

Educação científica como estratégia pedagógica para formação de professoras. Veredas - Revista de Estudos Linguísticos. Juiz de Fora: UFJF, v.23, n. 2, p. 144-161, 2019.

Recebido em 01de março de 2020

Aceito em 01 de junho de 2020 